\title{
Comparison of Early and Conventional Soybean Production Systems for Yield and other Agronomic Traits
}

\author{
Ouertani Khaled', Evandrew Washington', Patricia Lage', Stella K. Kantartzi ${ }^{2}$, David A. Light- \\ foot $^{2}$, and My Abdelmajid Kassem ${ }^{1 *}$
}

1 Plant Genomics \& Biotechnology Lab, Department of Biological Sciences, Fayetteville State University, Fayetteville, NC, USA. ${ }^{2}$ Department of Plant, Soil, and Agricultural Systems, Southern Illinois University, Carbondale, IL, USA.

Received: April 26, 2010 / Accepted: May 21, 2010

\section{Abstract}

$\mathbf{T}$ he early soybean production system (ESPS) was reported to be beneficial for yield compared to the conventional soybean production system (CSPS) and is widely used in the Southern USA. The objective of this study was to compare yield, yield components, root traits, and shoot traits in ESPS (April planting) and CSPS (June planting) in NC Sandhills using a recombinant inbred line (RIL) population, 'Hartwig' by 'Flyer' $(n=92)$. The population was grown in Spring Lake, NC in 2008 at a density of 16 seeds $\mathrm{m}^{-2}$. The traits measured were days to germination, days to flowering, plant height, seed weight, seed number, pod number, harvest index, root fresh weight, root dry weight, shoot fresh weight, shoot dry weight, maximum root length, and lateral root number. The survival rate ranged from 83.7 to $90.22 \%$ for ESPS; however, it was $21.74 \%$ for CSPS. Significant differences were observed for almost all traits measured in ESPS (April) compared to CSPS (June) apart from fresh root weight and lateral root number. An average increase in flowering time of 9 days was observed in CSPS compared to ESPS. On the other hand, several traits showed a significant mean decrease in CSPS compared to ESPS as plant height by $41.96 \%$, seed weight by $74.7 \%$, harvest index by $73.3 \%$, pod number by $65.2 \%$, and seed number by $64.9 \%$. The means for root fresh weight, root dry weight, shoot fresh weight, shoot dry weight, maximum root length, and lateral root numbers are shown in Table 2 for both ESPS and CSPS. The results indicated an average decrease of $40.4 \%$ in root fresh weight, of
$70.2 \%$ in root dry weight, of $\mathbf{6 8 . 1} \%$ in shoot fresh weight, of $80.1 \%$ in shoot dry weight, and of $83.3 \%$ in maximum root length in CSPS compared to ESPS. However, lateral root numbers increased by an average of $12.7 \%$ in CSPS compared to ESPS. Therefore, CSPS may not be appropriate for soybean at least in NC Sandhills.

Key Words: ESPS, CSPS, soybean, yield, root traits, shoot traits.

\section{Introduction}

The early soybean production system (ESPS, April) was reported to be beneficial for yield compared to the conventional soybean production system (CSPS, May-June) and is widely used in the Southern USA (Heatherly, 1996; Boquest, 1998; Heatherly et al., 2001; Heatherly and Smith, 1999, 2004; Bowers, 1995; Taylor et al., 2005). Akhter and Sneller (1996) reported that planting dates (April \& June) and stem termination (determinate vs. indeterminate maturity group IV lines) had no effects on yield. However, significant genotype $x$ planting dates interactions were observed for other traits such as plant height, number of branches, node numbers, and pod number per branch (Akhter and Sneller, 1996).

Several studies showed significant differences between ESPS and CSPS in yield and its components in many soybean cultivars, populations, and environments (Heatherly et al., 2001; Cober and Voldeng, 2001; Edwards and Purcell, 2005). For example,

\footnotetext{
* Corresponding author: mkassem@uncfsu.edu.
} 
Ray et al. (2008) found significant differences of plant height, seed yield, seed size, maturity date, lodging, protein, and oil contents in eight modified fatty acid lines (MFALs) and four cultivars grown in ESPS (May) and CSPS (June) in SC.

Diseases such as soybean cyst nematode (SCN), sudden death syndrome (SDS), soybean rust, defoliation, and decreased leaf area index (LAI), by insect and/or herbivore damage, and decreased canopy light interception (LI), can reduce considerably yields in many cultivars and environments (Hnetkovsky et al., 1996; lqbal et al., 2001; Concibido et al., 2002). Board (2010) demonstrated that defoliation reduced significantly yield, LI, and LAI in soybean. Additionally, it was shown that reduced yield is mainly due to reduced photosynthetic rates (reduced LAI and LI), short grain-filling period, and loss of leafstored photosynthate, due to defoliation (Ingram et al., 1981; Board, et al., 1994, 1997, 2010).

Row spacing is another factor that affects yield and its components (Ball et al., 2000; Edwards and Purcell, 2005; Ashlock et al., 2000). The average row-spacing recommended for soybeans grown in US southern environments is 25 seeds $\mathrm{m}^{-2}$ (Ashlock et al., 2000; Heatherly et al., 2001 ; Edwards and Purcell, 2005; Heitholt et al., 2005; Edwards et al., 2005). However, several studies showed that "narrow row spaced-soybeans" $(<19 \mathrm{~cm})$ were grown routinely in Southern USA because of increased yield especially in short-season soybeans (Ball et al., 2000; Edwards and Purcell, 2005). A relatively recent study compared yields of 3 maturity group III cultivars in row spaces $18,36,54$, and $71 \mathrm{~cm}$ in North TX and found that only one cultivar showed an increase in yield in 54 and 71 row spaces (Heitholt et al., 2005). The same study compared yields of 14 maturity group IV cultivars in row spaces 18 and $71 \mathrm{~cm}$ in Southern TX; however, no significant differences were shown in yields of these cultivars vis-à-vis row spacing (Heitholt et al., 2005).

Root biology is increasingly studied because of the importance of extensive root systems in water deficit tolerance (WDT) (Li et al., 2005; Bing et al., 2005; Lambers et al., 2006). Therefore the study of root traits is very important to identify genes involved in root development and understand their functions. For example, a positive correlation between the ratio of root to shoot weight and WDT has been reported (Price et al., 1997; Li et al., 2005).

The objective of this study was to compare yield and yield components along with other agronomic traits in ESPS (April) and CSPS (June) of 2008 in NC Sandhills using 'Flyer' by 'Hartwig' recombinant inbred line population $(\mathrm{FxH}, \mathrm{n}=92$; Kazi et al., 2007).

\section{Materials and Methods}

\section{Plant Material}

In this study, we used a soybean [Glycine max (L.) Merr.] F5:1 2-derived recombinant inbred line (RIL) population derived from 'Flyer' by 'Hartwig' ( $F x H, n=92$; Kazi et al., 2007). The FxH RIL population was provided to us by Dr. David Lightfoot of SIUC in 2008.

'Hartwig' by 'Flyer' recombinant inbred line (RIL) population used here was developed in SIUC and was extensively studied for quantitative trait loci (QTL) analysis of several important agronomic traits (Kazi et al., 2007, 2008). The parent 'Hartwig' was a mid-group $V$ maturity soybean cultivar, characterized by determinate growth habits, and was released for resistance to SCN (Kazi et al., 2007). The parent 'Flyer' was a maturity group IV BC3F2-derived line, characterized by indeterminate growth habits, and was released for lodging resistance and high seed yield (Kazi et al., 2007). The derived recombinant inbred lines of this population showed semi-determinate to determinate growth habits (Kazi et al., 2007).

\section{Growth Conditions}

Four seeds of 'Flyer', 'Hartwig', and each RIL were grown in pots of $15 \mathrm{~cm} \times 14 \mathrm{~cm}$ (diameter $\times$ height) containing potting soil in two groups, the first, at the beginning of April 2008 (ESPS) and the second at the beginning of June 2008 (CSPS). The plants were kept in the greenhouse at $25^{\circ} \mathrm{C} \pm 1^{\circ} \mathrm{C}$ under natural daylight for 3 weeks. After 3 weeks, the two groups of plants were transferred into a field in Spring Lake, Harnett County, NC [35.17N, -78.97W, and $276 \mathrm{ft}$. above sea level] at the end of April (ESPS) and June (CSPS), respectively. The plants were kept in the field, watered every other day until maturity of all RILs and the parents 'Flyer' and 'Hartwig' (1 35 days after planting, Kazi et al., 2007). No pesticides or herbicides were applied to the plants neither in the greenhouse nor in the field. The row-spacing and the spaces between individual plants in all rows were $30 \mathrm{~cm}$ which generated a 16 seeds/plants $\mathrm{m}^{-2}$, in the field. T e soil type in Spring Lake, NC - Carolina Sandhills - is sandy (rich in sand).

\section{Trait Measurements}

Several traits were measured in both groups of this population. The days to germination were recorded in the greenhouse while yield and its components (days to flowering, plant height, seed numbers, pod numbers, and seed weight) were recorded in the field. Except of days to germination, the other 4 traits were measured just before harvesting. After harvest, the root (maximum root length (MRL), lateral root number (LRN), root dry weight (RDW) and root fresh weight (RFW)) and shoot (shoot fresh weight (SFW) and shoot dry weight (SDW)) traits were measured. In addition, the ratio of root fresh weigh to root dry weigh (RFW/RDW), and of shoot fresh weigh to shoot dry weight (SFW/SDW) were calculated. To measure RDW and SDW, plant roots and shoots were placed in an oven at $650 \mathrm{C}$ for 48 hours. All these measurements were taken for both groups I (ESPS) and II (CSPS) of plants.

\section{Data Analysis}

Means, ranges and standard errors of the various traits were calculated for the RIL lines from raw data for both ESPS and CSPS. Differences between the two production systems for each trait were tested by independent samples $t$ test. Additionally, Pearson correlation coefficients were calculated. All tests were performed on JMP 8.0.2 (SAS Institute Inc., Cary, NC, USA). 


\section{Results}

The survival rate ranged from 83.7 to $90.22 \%$ for ESPS (April); however, it was $21.74 \%$ for CSPS (June). The extremely low survival rates of plants in June was mainly due to extreme drought conditions in the Carolina Sandhills (Summer 2008), and extreme plant damage by insects and herbivores observed particularly in CSPS (June) plants.

Significant differences were observed for almost all traits measured in ESPS (April) compared to CSPS (June) apart from harvest index, fresh root weight and lateral root number (Tables 1 and 2). An average increase in flowering time of 9 days was observed in CSPS compared to ESPS (Table 1). Several traits showed a significant mean decrease in CSPS compared to ESPS as plant height by $41.96 \%$, seed weight by of $74.7 \%$, pod number by $65.2 \%$, and seed number by $64.9 \%$ (Table 1 ). The differences in means and ranges for yield components (seed weight, number of pods and number of seeds) between ESPS and CSPS are shown comparatively in Figure 1.

The means for all other agronomic traits as root fresh weight, root dry weight, shoot fresh weight, shoot dry weight, maximum root length, and lateral root numbers are shown in Table 2 for both ESPS and CSPS. The results indicated an average decrease of $40.4 \%$ in root fresh weight, of $70.2 \%$ in root dry weight, of $68.1 \%$ in shoot fresh weight, of $80.1 \%$ in shoot dry weight, and of $83.3 \%$ in maximum root length in CSPS compared to ESPS (Table 2; Fig.2). However, lateral root numbers increased by an average of $12.7 \%$ in CSPS compared to ESPS (Table 2; Fig. 2).

The yield traits (seed weight, number of seeds and number of pods) and rest of agronomic traits studied (root fresh weight, root dry weight, shoot fresh weight, shoot dry weight, maximum root length and lateral root number) were significantly correlated in both ESPS $(\mathrm{r}=0.870 * * *$ to $\mathrm{r}=0.996 * * *$, where $*=$ significance at the $0.05, * *=$ significance at the 0.01 and $* * *=$ significance at the 0.001$)$ and CSPS ( $r=0.612 *$ to $r=0.999 * * *)$.

Table 1. Averages and ranges of flowering time, plant height, seed weight, harvest index, pod number, and seed numbers of 'Hartwig' by 'Flyer' RIL population in ESPS (April) and CSPS (June).

\begin{tabular}{|c|c|c|c|c|}
\hline \multirow[b]{2}{*}{ Trait } & \multicolumn{2}{|c|}{ Average ( \pm St. Error) } & \multicolumn{2}{|c|}{ Range } \\
\hline & ESPS & CSPS & ESPS & CSPS \\
\hline Days to Germination (DG) & $4.74( \pm 0.09) a^{*}$ & $3.90( \pm 0.16) b$ & $3-7$ & $3-6$ \\
\hline Flowering time (FT) & $40.68( \pm 0.48) b$ & $49.15( \pm 1.28) a$ & $34-50$ & $42-59$ \\
\hline Plant height $(\mathrm{PH}$, in $\mathrm{cm})$ & $73.42( \pm 2.28) a$ & $42.57( \pm 4.25) \mathrm{b}$ & $33-131$ & $35-96$ \\
\hline Seed weight (SW, in g) & $8.30( \pm 1.26) a$ & $2.09( \pm 1.15) b$ & $0.1-65$ & $0.02-22.4$ \\
\hline Harvest inde $x(\mathrm{HI})$ & $0.03( \pm 0.00) a$ & $0.03 \_( \pm 0.01) a$ & $0.01-0.05$ & $0-0.11$ \\
\hline Pod number (PN) & $51.45( \pm 6.10) a$ & $17.90( \pm 7.95) b$ & $3-276$ & $0-115$ \\
\hline Seed number (SN) & $153.53( \pm 13.67) a$ & $53.85( \pm 23.42) b$ & $12-542$ & $0-336$ \\
\hline
\end{tabular}

*a-b column wide comparison. Level not connected by same letter are significantly different. All comparisons were done using $t$ test at $5 \%$ level of significance.

Table 2. Averages and ranges of root fresh weight (RFW), root dry weight (RDW), shoot fresh weight (SFW), shoot dry weight (SDW), maximum root length (MRL), and lateral root number (LRN) of 'Hartwig' by 'Flyer' RIL population in ESPS (April) and CSPS (June).

\begin{tabular}{|c|c|c|c|c|}
\hline \multirow[b]{2}{*}{ Trait } & \multicolumn{2}{|c|}{$\begin{array}{l}\text { Average } \\
( \pm \text { St. Er) }\end{array}$} & \multicolumn{2}{|c|}{ Range } \\
\hline & ESPS & CSPS & ESPS & CSPS \\
\hline Root fresh weight (RFW, g) & $75.97( \pm 8.06) a$ & $45.20( \pm 13.21) a$ & $3-419$ & $1-233$ \\
\hline Root dry weight (RDW, g) & $36.91( \pm 3.96) a$ & $11.00( \pm 3.15) b$ & $4-241$ & $1-58$ \\
\hline Shoot fresh weight (SFW, g) & $232.74( \pm 28.96) a$ & $74.20( \pm 28.74) b$ & $6-1351$ & $2-568$ \\
\hline Shoot dry weight (SDW, g) & $162.99( \pm 21.24) a$ & $22.70 \_( \pm 6.34) \mathrm{b}$ & 3-1005 & $4-137$ \\
\hline Maximum root length (MRL, $\mathrm{cm}$ ) & $122.22( \pm 16.12) a$ & $20.35( \pm 3.34) b$ & $10-592$ & $6-77$ \\
\hline Lateral root number (LRN) & $15.75( \pm 0.64) a$ & $17.70( \pm 2.07) a$ & $8-34$ & $6-33$ \\
\hline
\end{tabular}

*a-b column wide comparison. Level not connected by same letter are significantly different. All comparisons were done using $t$ test at $5 \%$ level of significance. 
Panel A

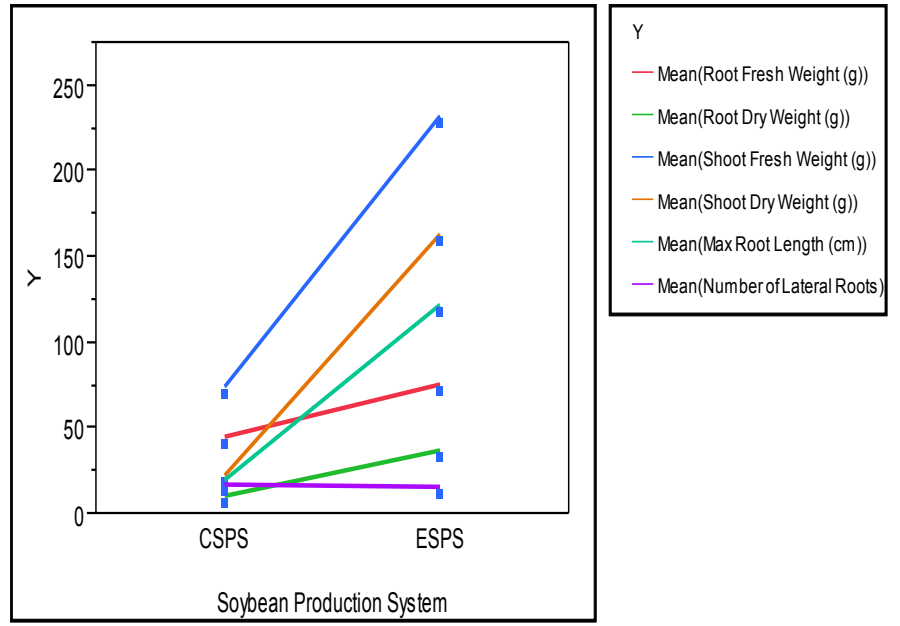

Figure 2. Positive and negative mean differences of agronomic traits (root fresh weight, root dry weight, shoot fresh weight, shoot dry weight, max root length and number of lateral roots) between ESPS and CSPS.

pared to ESPS. However, the range for lateral root numbers remained relatively unchanged in CSPS compared to ESPS.

Early-planted soybeans were reported to be drought tolerant and high yielding in many parts of US (Akhter and Sneller, 1996; Edwards et al., 2005; Edwards and Purcell, 2005), and have been adopted by many farmers and growers, especially in the Midsouthern US (Heatherly et al., 1999). Heatherly and Smith (2004) reported that yield from cultivars of maturity groups IV and $V$ was similar. We observed significant yield loss (yield difference) in both parents 'Hartwig', 'Flyer', and their progeny (HxF RILs) in this study. This is might be due to extreme drought conditions in the Carolina Sandhills, particularly in summer 2008 (National Climatic Data Center, 2008). Also, many herbivores, ants, and insects damaged the plants, especially the June group (CSPS). In a recent study, Ray et al. (2008) found significant differences of plant height, seed yield, seed size, maturity date, and lodging for eight modified fatty acid lines (MFALs) and four cultivars grown using ESPS and CSPS with planting dates in May (ESPS) and June (CSPS) in SC.

The results presented here demonstrated clearly that there were significant differences in ESPS and CSPS for almost all traits measured including yield and yield components. There were significant losses of yield, its components as well as shoot and root traits in CSPS. Therefore, CSPS may not be appropriate for soybean at least in NC Sandhills. However, extreme drought conditions in the Carolina Sandhills, particularly in spring-summer 2008, might play a role in the excessive yield and biomass loss observed here and these experiments should be repeated in other growing seasons.

\section{Acknowledgments}

We thank Samantha Woods, Wendy Holland, Leslie Moore, James Walker, and Mrs. Pam Ratcliff for taking care of the plants in the greenhouse and in the field. 


\section{References}

Akhter M, and CH Sneller (1996) Yield and yield components of early maturing soybean genotypes in the Mid-South. Crop Sci 36: 877882.

Ashlock LO, R Klerk, G Huitink, T Keisling, and ED Vories (2000) Planting practices. In Arkansas soybean handbook. MPV 197. Coop. Exp. Serv. University of Arkansas, Little Rock, AR. p. 35-49.

Ball RA, LC Purcell, and ED Vories (2000) Optimizing Soybean Plant Population for a Short-Season Production System in the Southern USA. Crop Sci 40: 757-764.

Bing Y, L Xiong, W Xue, Y Xing, L Luo, and C Xu (2005) Genetic analysis for drought resistance of rice at reproductive stage in field with different types of soil. Theor Appl Genet 111:1127-1136.

Board JE, AT Wier, and DJ Boethel (1994) Soybean yield reductions caused by defoliation during mid to late seed filling. Agron J 86: 1074-1079.

Board JE, AT Wier, and DJ Boethel (1997) Critical light interception during seed filling for insecticide application and optimum soybean grain yield. Agron J 89: 369-374.

Board JE, S Kumudini, J Omielan, E Prior, and CS Kahlon (2010) Yield Response of Soybean to Partial and Total Defoliation during the Seed-Filling Period. Cop Sci 50: 703-712.

Boquest DJ (1998) Yield and risk utilizing short-season soybean production in the mid-southern USA. Crop Sci 38: 1004-1011.

Bowers GR (1995) An early soybean production system for drought avoidance. J Prod Agric 8: 112-119.

Cober ER, and HD Voldeng (2001) A New Soybean Maturity and Photoperiod-Sensitivity Locus Linked to E1 and T. Crop Sci 41: 698-701.

Concibido VC, LA Vallee, P Mclaird, N Pineda, J Meyer, L Hummel, J Yang, K Wu, and K Delannay (2002) Introgression of a quantitative trait locus for yield from Glycine soja into commercial soybean cultivars. Theor Appl Genet 106: 575-582.

Edwards JT, and LC Purcell (2005) Soybean yield and biomass responses to increasing plant production among diverse maturity groups: I. Agronomic characteristics. Crop Sci 45: 1770-1777.

Edwards JT, and LC Purcell, and DE Karcher (2005) Soybean yield and biomass to increasing plant population among diverse maturity groups. II. Light interception and utilization. Crop Sci 45: 17781785.

Heatherly LG (1996) Yield and Germinability of Seed from Irrigated and Nonirrigated Early- and Late-Planted MG IV and V Soybean. Crop Sci 36: 1000-1006.

Heatherly LG, and JR Smith (2004) Effect of soybean stem growth habit on height and node number after beginning bloom in the Midsouth- ern USA. Crop Sci 44: 1855-1558.

Heatherly LG, and SR Smith (1999) Yield and economics of traditional and early soybean production system (ESPS) seedlings in the Midsouthern USA. Field Crops Res 63: 35-45.

Heatherly LG, CD Elmore, RA Wesley, and SR Spurlock (2001) Row spacing and weed management systems for nonirrigated early soybean production system plantings in the Midsouthern USA. Crop Sci 41: 784-791.

Heitholt JJ, JB Farr, and R Eason (2005) Planting Configuration x Cultivar Effects on Soybean Production in Low-Yield Environments. Crop Sci 45: 1800-1808.

Hnetkovsky N, SJC Chang, TW Doubler, PT Gibson, and DA Lightfoot (1996) Genetic mapping of loci underlying Weld resistance to soybean sudden death syndrome (SDS). Crop Sci 36: 393-400.

Ingram KT, DC Herzog, KJ Boote, JW Jones, and CS Barfield (1981) Effects of defoliating pests on soybean canopy $\mathrm{CO} 2$ exchange and reproductive growth. Crop Sci 21: 961-968.

lqbal MJ, K Meksem, VN Njiti, MA Kassem, and DA Lightfoot (2001) Microsatellite markers identity three additional quantitative trait loci for resistance to soybean sudden-death syndrome (SDS) in Essex $x$ Forrest RILs. Theor Appl Genet 102:187-192.

Kazi S, J Shultz, J Afzal, J Johnson, VN Niiti, and DA Lightfoot (2008) Separate loci underlie resistance to root infection and leaf scorch during soybean sudden death syndrome. Theor Appl Genet 116: 967-977.

Kazi S, VN Niiti, TW Doubler, J Yuan, MJ Iqbal, S Cianzio, and DA Lightfoot (2007) Registration of the Flyer by Hartwig recombinant inbred line mapping population. J Plant Regis 1: 175-178.

Lambers H, MW Shane, MD Cramer, SJ Pearse, and EJ Veneklaas (2006) Root structure and functioning for efficient acquisition of phosphorus: matching morphological and physiological traits. Annals of Botany 98: 693-713.

Li Z, P Mu, C Li, H Zhang, Z Li, Y Gao, and X Wang (2005) QTL mapping of root traits in a doubled haploid population from a cross between upland and lowland japonica rice in three environments. Theor Appl Genet 110 : 1244-1252.

National Climatic Data Center (2008) http://www.ncdc.noaa.gov/oa/ ncdc.html.

Price AH, DS Virk, and AD Tomos (1997) Genetic dissection of root growth in rice (Oryza sativa L.). I: a hydroponic screen. Theor Appl Genet 95: 132-142.

Ray CL, ER Shipe, and WC Bridges (2008) Planting date influence on soybean agronomic traits and seed composition in modified fatty acid breeding lines. Crop Sci 48: 181-188.

Taylor RS, DB Weaver, CW Wood, and EV Stanten (2005) Nitrogen application increases yield and early dry matter accumulation in late-planted soybean. Crop Sci 45: 854-858. 